\title{
The effect of natural clays catalysts on thermal degradation of a plastic waste mixture
}

\author{
Miuţa Rafila Filip ${ }^{1, a}$, Aurelia Pop ${ }^{2}$, loana Perhaiţa ${ }^{2}$, \\ Roxana Truşcă ${ }^{3}$ and Tiberiu Rusu ${ }^{1}$ \\ ${ }^{1}$ Technical University of Cluj-Napoca, Faculty of Materials and Environmental Engineering, \\ 103-105 Muncii Avenue, 400641, Cluj-Napoca, Romania \\ ${ }^{2}$ Babeş-Bolyai University, Raluca Ripan Institute for Research in Chemistry, 30 Fântânele Street, \\ 400294 Cluj-Napoca, Romania \\ ${ }^{3}$ Metav Research-Development, 31 C.A. Rosetti Street, 020011, Bucharest, Romania \\ email: afilip_miuta@yahoo.com
}

Keywords: plastic waste, thermal degradation, natural clay, GC-MS, FTIR, UV-Vis.

\begin{abstract}
The thermal and catalytic degradation of a plastic wastes mixtures using two types of natural clays catalysts has been carried out in order to obtaining liquid oils with potential use in the chemical industry. Thus, the polymer waste mixture (PWM) of polystyrene (PS), poly(ethylene terephthalate) (PET) and poly(vinyl chloride) (PVC) were thermally degraded at $420{ }^{\circ} \mathrm{C}$ in absence and presence of studied catalysts in mass ratio $1: 10$, catalyst/PWM. The catalysts were characterized by $\mathrm{N}_{2}$ adsorption-desorption isotherms (BET), Scanning Electron Microscopy (SEM) and Fourier-transform infrared spectrometry (FTIR) for determined the structural and textural properties. The degradation of plastic wastes produces gases, liquids and solid residue products. The effect of the catalyst types on the yields and distribution of end-products obtained by thermal and catalytic degradation of mixed plastic waste has been studied. The yields of liquid oils fractions were calculated between $54.98 \mathrm{wt} . \%$ and $62.18 \mathrm{wt} . \%$. The liquids and solid products were analyzed by different analytical techniques: gas chromatography mass spectrometry (GC-MS), ultraviolet visible spectroscopy (UV-Vis) and/or FTIR, in order to establish the chemical compositions. The GC-MS results showed that the liquid products contain in principal monoaromatic compounds like styrene, toluene, ethylbenzene or $\alpha$-methylstyrene. The FTIR and UV-Vis spectra of products indicated the specific vibration bands or transitions between electronic energy levels of the functional groups of the constituent compounds.
\end{abstract}

\section{Introduction}

The amount of plastics on Earth is enormous, mostly of these plastics have replaced materials such as glass, ceramic or wood in the manufacture of everyday use objects. The management of the plastic wastes became a major concern, because of our consumer lifestyle. Recycling of polymer waste can contribute to the solution of pollution problems and the reuse of this cheap and abundant source of chemicals. Pyrolysis is a suitable recycling technique for converting the plastic waste into monomers, fuels or other valuable materials by thermal cracking processes. This method can be applied to transform both thermoplastics and thermosets, moreover, it is suitable for the treatment of plastic wastes mixtures [1].

Thermal cracking of seven components mixed plastics into oils/waxes was investigated by thermal cracking process. The presence of PS, PVC and PET in mixed plastics increased the formulation of carbon monoxide and carbon dioxide in the gas and benzene, toluene, xylenes, styrene in the liquid (oil/waxes) products [2].

Polymer wastes generally contain various polymers together, in this way any component can affect the thermal decomposition reactions of the others. Significant amount of various chlorinated, brominated and both chlorinated and brominated products are released during the decomposition of polymer mixtures of PVC, PET and ABS [3]. Stepwise pyrolysis and/or addition of adsorbents can be used to reduce the chlorine content of the products generated in PVC containing plastic wastes pyrolysis [4]. Pyrolysis of real waste polymer samples show that the pyrolysis liquids contain valuable chemicals as styrene, ethyl-benzene, toluene, etc. [5]. 
Catalytic pyrolysis process of the polymers depends on the chemical and physical characteristics of the catalysts, as well as on the chemical and structural nature of the polymers. Catalysts for plastic cracking may be either homogeneous or heterogeneous, although the former are rather more the exception than the rule [6]. A great variety of of catalytic materials have been used for the catalytic cracking of plastics: homogeneous catalysts [7,8], acid mesoporous materials $[9,10]$, non-acid mesoporous solids [11], FCC catalysts [12], zeolites [13-15], metallic oxides [16-18], natural clays and aluminum pillared clays [19-21] etc. The clays investigated include montmorillonite, saponite, albite, pyrophyllite and halloysite. They possess a layered structure which can be converted into a two-dimensional network of interconnected micropores by intercalation of molecular moieties. These materials show a mild acidity and an accessible pore size structure. The consideration of pillared clays as possible catalysts for plastic cracking is mainly supported by the fact that their acidity is weaker in strength than that of zeolites [21,22].

Some of mentioned studies have been carried out with single plastics or simple mixtures of plastics. But the real waste samples are complex mixtures of plastics, which include PVC and PET. These polymers can create different problems due to oxygenated and chlorinated components that are obtained at their degradation.

The aim of present work was to study the thermal degradation of a plastic waste mixture (PWM) into liquid products on two types of natural Romanian clay catalysts. Influence of the type of catalysts on the yields and on the distribution of end-products obtained by thermal and catalytic degradation of PWM was investigated. The characterization of the thermal and catalytic degradation products has been made in order to provide useful information for potential industrial applications. The use of the Romanian natural clay catalysts for study of thermal and catalytic degradation of PWM could be a suitable way for cost reduction of a catalytic process and to obtain valuable chemicals for industry.

\section{Experimental}

\section{Plastic waste samples}

The following materials were used to prepare the plastic waste mixture for the experiments: the sources of polystyrene waste (PS) were vessel detergent boxes and disposable glasses and plates; the poly(ethylene terephthalate) waste (PET) were obtained from beverage bottles and poly(vinyl chloride) waste (PVC) were provided from PVC products manufacturing Romanian company. All the plastic materials were cut into small pieces approximately $5 \times 5 \mathrm{~mm}$ and used for the thermal degaradation experiments. The plastic waste mixture (PWM) contains PS, PET and PVC in a mass ratio of 18:4:3. The proportions used in the plastic waste mixture was based on the composition proposed by other authors as representative of municipal plastic wastes in Europe [4].

\section{Catalysts and their characterization}

The catalysts used in this study were two samples of Romanian natural clays from different areas: Vadu Crişului clay (Bihor county) and Lugoj clay (Timiş county).

The catalysts were subjected to a heating treatment in an oven in two stages. The first was made at $200{ }^{\circ} \mathrm{C}$ for 2 hours for remove the adsorbed water from the mesopores, then followed the second heat treatment at $500{ }^{\circ} \mathrm{C}$ for 5 hours to activate the active centres. Then, the catalysts were kept in a desiccator for the experiments.

The surface area and porosity characteristics of the calcined catalysts were determined by nitrogen adsorption-desorption isotherms at $77 \mathrm{~K}$ using a Micromeritics TriStar II 3020 instrument. The adsorption-desorbsion curves of the isotherms were recorded and the surface area measurements were done according to the BET (Brunauer-Emmett-Teller) method. The pore size distributions were obtained applying the BJH (Barrett, Joyner, Halenda) method on isotherm desorption branch and the micropores area and volume were obtained applying the t-plot (de Boer) method. 
External surface, morphology and structure of catalysts were visualized by Scanning Electron Microscopy (SEM) and the chemical compositions were determined by EDAX (Energy Dispersive Analysis of X-Rays) method using a QUANTA 133 Electron Microscope (FEI Company).

Structural information of catalysts were obtained by FTIR spectra registered with a JASCOFTIR 610 Fourier-transform infrared spectrometer (FTIR) in the $4000-400 \mathrm{~cm}^{-1}$ wavenumber range, using the $\mathrm{KBr}$ pellet technique.

\section{Thermal degradation procedure}

Thermal degradation of the PWM was performed in a tubular glass reactor $(175 \mathrm{~mm} \times 33 \mathrm{~mm}$ ID) heated externally by an electric furnace. A thermometer with thermocouple (K type) was fixed inside the reactor and the temperature was controlled by external PID controller. The PWM and the catalyst in a mass ratio of $10 / 1, \mathrm{w} / \mathrm{w}$, was added in the reactor. Before the starting of the experiments, the nitrogen gas was continuously passed through the installation with a flow rate of $30 \mathrm{~mL} \cdot \mathrm{min}^{-1}$ for 10 minutes to remove the air. Then it was followed the thermal decomposition step by heated at a rate of $20^{\circ} \mathrm{C} \cdot \mathrm{min}^{-1}$ up to $420^{\circ} \mathrm{C}$. The formed gaseous products passed through water cooled condenser $\left(0-4{ }^{\circ} \mathrm{C}\right)$ the condensable gases were collected as a liquid product. The incondensable gases were collected in a special bag as a gaseous product. In the glass reactor remain the used catalyst and the formed residue. The obtained products were analyzed by different analytical techniques.

\section{Analysis of Products}

The yields of obtained products by thermal and catalytic degradation of PWM (L - liquid, R residue and $\mathrm{G}$ - gases) were calculated using the Eq. 1-3. The liquid products and the collected solids (products in the reactor after the degradation process) were weighted directly. The yields of gaseous products are calculated as a general rule by difference.

$$
\begin{aligned}
& \mathrm{L}\left(\text { wt.\%) }=\frac{\mathrm{m}_{\mathrm{L}}}{\mathrm{MPwM}_{\mathrm{PWM}}} \cdot 100\right. \\
& \mathrm{R}\left(\text { wt.\%) }=\frac{\mathrm{m}_{\mathrm{R}}}{\mathrm{M}_{\mathrm{PWM}}} \cdot 100\right. \\
& \mathrm{G}(\text { wt.\%) }=100-(\mathrm{L}+\mathrm{R})
\end{aligned}
$$

where $m_{L}$ is the weight of liquid product $[\mathrm{g}], \mathrm{m}_{\mathrm{R}}$ the weight of residue $[\mathrm{g}]$ and $\mathrm{M}_{\mathrm{PWM}}$ the weight of plastic waste mixture [g].

The GC-MS analysis of liquid products was performed on a Hewlett Packard HP 5890 Series II GC gas chromatograph interfaced to a Hewlett Packard 5972 Series mass selective detector using a Zebron ZB-5MS capillary column (30 m x $0.25 \mathrm{~mm}$ ID $\times 0.25 \mu \mathrm{m}$ film thickness) with the following temperature program: the initial temperature of $40{ }^{\circ} \mathrm{C}$ was held for $10 \mathrm{~min}$., increased with $4{ }^{\circ} \mathrm{C} \cdot \mathrm{min}^{-1}$ at $280^{\circ} \mathrm{C}$ and maintained at this final temperature for $10 \mathrm{~min}$. Total run time was $80 \mathrm{~min}$. The helium was the carrier gas. Temperature of the injector was $250{ }^{\circ} \mathrm{C}$. The volume of injected sample was $0.1 \mu \mathrm{L}$. MS mode was carried out in full scan, with the scan range of 10-700 amu and the scan speed up to $1800 \mathrm{amu} \cdot \mathrm{s}^{-1}$. The ionization intensity of $70 \mathrm{eV}$ was used. The acquisition of chromatographic data was performed by means of the HPchem software. All mass spectra obtained by GC-MS were interpreted based on an automatic library search (DATABASE/wiley6.1).

The liquid products were analyzed by a Fourier-transform infrared spectrometry (FTIR) using a JASCO-FTIR 610 spectrometer, in the $4000-400 \mathrm{~cm}^{-1}$ wavenumber range, using the liquid film technique. The FTIR analysis of solid samples were perform using the KBr pellet technique.

The liquid products were analyzed also by ultraviolet-visible spectroscopy (UV-Vis) using a UNICAM UV-4 spectrometer equipped with photomultiplier detector. All UV-Vis spectra were records in the range of 190-400 nm, $4 \mathrm{~nm}$ bandwidth, cell path length of $1 \mathrm{~cm}$ and hexane as reference. The FTIR and UV-Vis spectra of all the studied samples were registered at room temperature. 


\section{Results and discussions}

\section{Catalysts characterization}

The nitrogen adsorption-desorption isotherms of the catalysts were presented in Fig. 1.
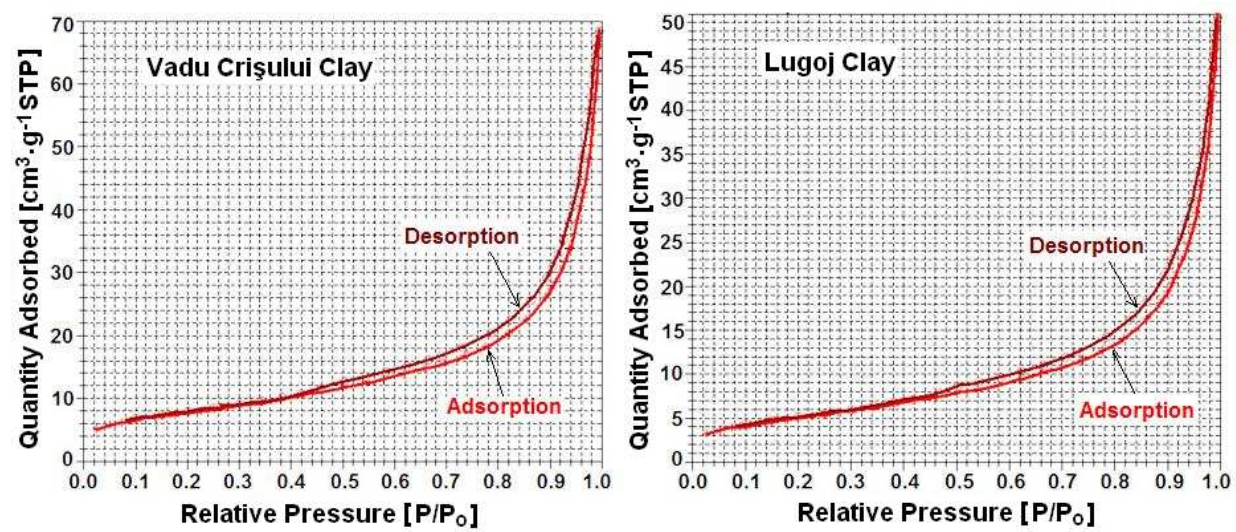

Fig. $1 . \mathrm{N}_{2}$ adsorption-desorption isotherms at $77 \mathrm{~K}$ of the studied catalysts.

The nitrogen adsorption-desorption isotherms shown in Fig.1 are predominantly type I (Langmuir) combined with type IV isotherm, according to International Union of Pure and Applied Chemistry (IUPAC) classification [23].

The adsorption isotherms suggest that the catalysts are meso- and macroporous materials. The microporous nature of these catalysts is indicated by the low adsorption volume at low relative pressure $\left(\mathrm{P} / \mathrm{P}_{\mathrm{o}}<0.1\right)$. When increase the relative pressure the capillary condensation taking place in mesopores, showing type IV isotherm behavior with its characteristic H4 hysteresis loop. This type of hysteresis loop is often associated with narrow slit-like pore that are usually found in solids consisting of aggregates or agglomerates of particles. Additionally, starting to the high relative pressures $\mathrm{P} / \mathrm{P}_{\mathrm{o}}>0.8$ we can observed a rapid grow of the $\mathrm{N}_{2}$ amount adsorbed, that indicate a secondary porosity (inter-particles) associated with meso- and macropores existence.

In Table 1 and Fig. 2 are presented the surface area and porosity characteristics and the pore size cumulative / derived distribution curves (pore volume, pore area) of the studied catalysts.

Table 1 Surface area and porosity characteristics of studied catalysts

\begin{tabular}{|c|c|c|c|c|c|c|}
\hline $\begin{array}{l}\text { Clay } \\
\text { Catalyst }\end{array}$ & $\begin{array}{l}\text { Specific } \\
\text { surface } \\
\text { area, BET }{ }^{\mathrm{a}} \text {, } \\
{\left[\mathrm{m}^{2} \cdot \mathrm{g}^{-1}\right]}\end{array}$ & $\begin{array}{l}\text { Micropores } \\
\text { area }{ }^{b} \\
{\left[\mathrm{~m}^{2} \cdot \mathrm{g}^{-1}\right]}\end{array}$ & $\begin{array}{l}\text { Micropore } \\
\text { volume } \mathrm{b}^{\mathrm{b}} \\
{\left[\mathrm{cm}^{3} \cdot \mathrm{g}^{-1}\right]}\end{array}$ & $\begin{array}{l}\text { Meso- \& } \\
\text { macropores } \\
\text { area }^{\mathrm{c}} \\
{\left[\mathrm{m}^{2} \cdot \mathrm{g}^{-1}\right]}\end{array}$ & $\begin{array}{l}\text { Meso- \& } \\
\text { macropores } \\
\text { volume } \\
{\left[\mathrm{cm}^{3} \cdot \mathrm{g}^{-1}\right]}\end{array}$ & $\begin{array}{l}\text { Average meso- } \\
\& \text { macropores } \\
\text { diameter }^{\mathrm{c}} \\
{[\AA]}\end{array}$ \\
\hline $\begin{array}{l}\text { Vadu } \\
\text { Crişului }\end{array}$ & 27.80 & 9.48 & 0.0013 & 28.32 & 0.108 & 153 \\
\hline Lugoj & 18.26 & 5.70 & 0.0003 & 20.57 & 0.081 & 157 \\
\hline
\end{tabular}

${ }^{\mathrm{a}}$ BET method; ${ }^{\mathrm{b}}$-plot method; ${ }^{\mathrm{c}} \mathrm{BJH}$ desorption method

The surface area is the measure of the catalyst activity of the same catalyst types and has a strong effect on the performance of catalytic process [22]. 

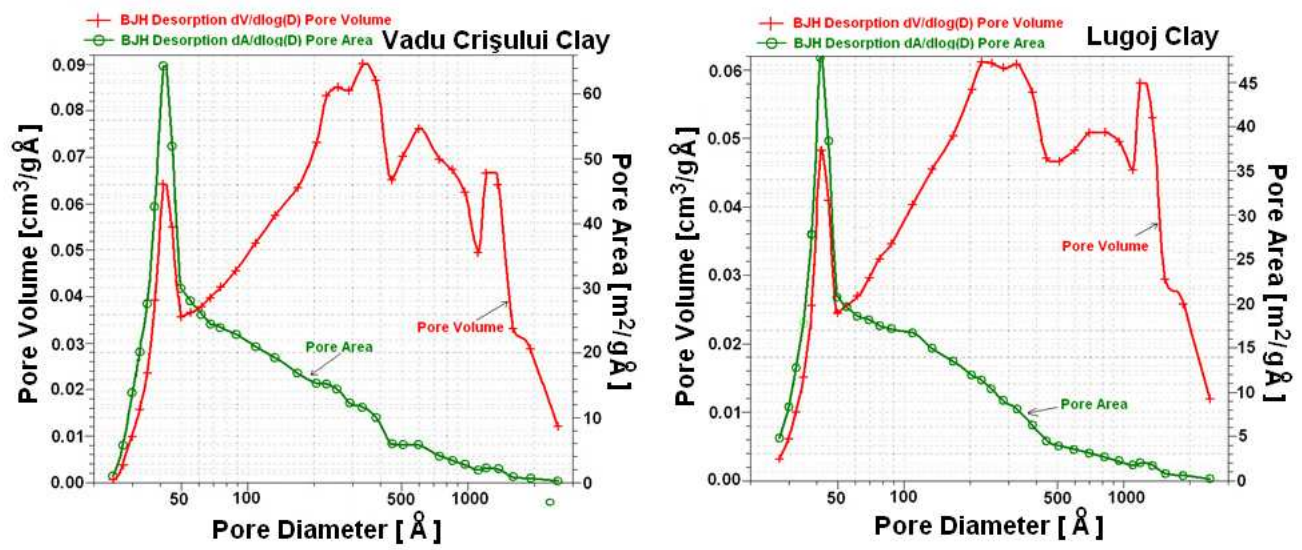

Fig. 2. Pore size cumulative / derived distribution curve of the studied catalysts

Thus, the Vadu Crişului clay catalyst has highest value of BET surface area of $27.80 \mathrm{~m}^{2} \cdot \mathrm{g}^{-1}$ and the value of meso- and macropore volume of $0.108 \mathrm{~cm}^{3} \cdot \mathrm{g}^{-1}$. The Lugoj clay catalyst has BET surface area and meso- and macropore volume of $18.26 \mathrm{~m}^{2} \cdot \mathrm{g}^{-1}$ and $0.081 \mathrm{~cm}^{3} \cdot \mathrm{g}^{-1}$ respectively.

The average pores diameter is $153 \AA$ for Vadu Crişului clay catalyst and $157 \AA$ for Lugoj clay catalyst and suggests a large number of macropores. There are small differences in pore distribution for both calatyst.

The chemical compositions (oxides wt.\%) of the calcined catalysts were determined from EDAX (Energy Dispersive Analysis of X-Rays) spectra are reported in Fig. 3.

Chemical composition of studied clay catalysts shows that $\mathrm{SiO}_{2}$ and $\mathrm{Al}_{2} \mathrm{O}_{3}$ are main components in both type of catalyst.

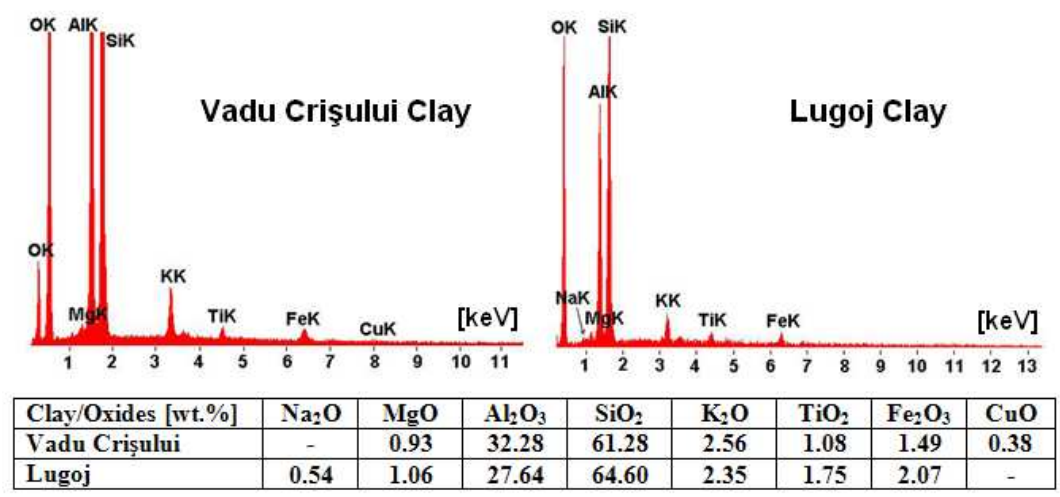

Fig. 3. EDAX spectra and chemical composition of the studied catalysts

Also, the catalysts contain minor amount of $\mathrm{K}_{2} \mathrm{O}, \mathrm{MgO}, \mathrm{TiO}_{2}$ and $\mathrm{Fe}_{2} \mathrm{O}_{3}$. The Vadu Crişului clay catalyst contains a small amount of $\mathrm{CuO}$ and the Lugoj clay catalyst contains a small amount of $\mathrm{Na}_{2} \mathrm{O}$. The Vadu Crişului clay is the caolinite type.

SEM images of studied catalysts used in thermal degradation of PWM were carried out in order to observe the morphology of these material and are presented in Fig. 4.

Fig. 4 shows the structure of studied clay catalysts which is constituted by different size particles and larger crystals. The morphology and different shapes are formed by agglomeration of the macropores. These images reveal a small variation in morphology, the Lugoj clay catalyst shows larger particle aggregates with smooth surfaces, while that of Vadu Crişului clay catalyst shows the formation of disordered structures. This confers to catalysts a highly heterogeneous internal structure. All the measures were carried out at the same full scale of $10 \mu \mathrm{m}$ for better correlation. Microporous structure is not observed by SEM. 

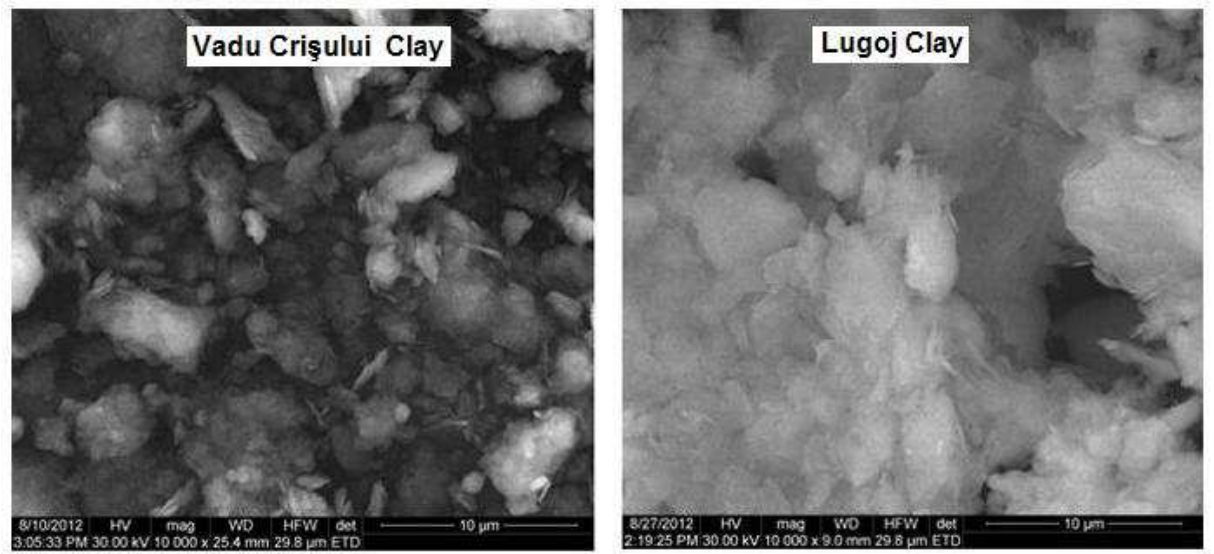

Fig. 4. SEM microphotographs of the studied catalysts

The FTIR spectra of studied catalysts are presented in Fig. 5. FTIR spectra can be useful in obtaining the structure information about catalysts about the channel size and the cation substitution $\left(\mathrm{Si}^{+4}\right.$ by $\left.\mathrm{Al}^{+3}\right)$, in the tetrahedral sites of zeolite minerals [24,25].

In Fig. 5 it can be observed, like in case of silicates [26], that the $\mathrm{Si}-\mathrm{O}-\mathrm{Si}$ asymetric stretch vibration are evidenced by the very strong absorption bands between 1000 and $1100 \mathrm{~cm}^{-1}$. The bands at 538 and $470 \mathrm{~cm}^{-1}$ appear due to $\mathrm{Al}-\mathrm{O}-\mathrm{Si}$ and $\mathrm{Si}-\mathrm{O}-\mathrm{Si}$ bending vibrations, respectively. The weak band from $800 \mathrm{~cm}^{-1}$ occurs due to the symetric stretch vibrations of internal oxygen bridges Si-O-Si. FTIR band from $930 \mathrm{~cm}^{-1}$ represents silanol $\mathrm{Si}-\mathrm{O}$ stretch vibration $[26,27]$.

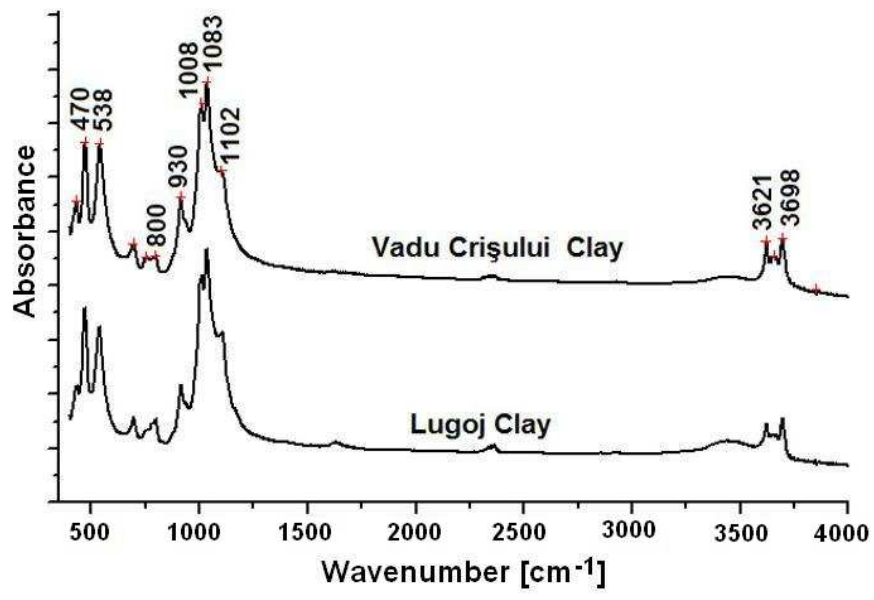

Fig. 5. FTIR spectra of the studied cataysts

\section{Yields of products}

The products obtained by thermal and catalytic degradation of polimer waste were classified in three classes: liquid, gas and residue. As known, the yields of these products depend on many parameters such as: temperature, polymer and catalyst type, experimental reactor, residence time of volatiles in reactor, etc. [1].

The yields of the obtained products at thermal degradation of PWM in presence of the clay catalysts were calculated according to the eq. (1-3) and are presented in Fig. 6.

The results show that the yields of liquid products obtained by the thermal degradation at $420{ }^{\circ} \mathrm{C}$ of PWM in absence and in presence of clay catalysts have high values between $54.98 \mathrm{wt} . \%$ (for PWM) and 62.18 wt.\% (for PWM-Vadu Crişului Clay). The amounts of residue obtained are around the 16-18 wt.\%. The residue contains a small amount of solid yellow-brown compound, deposited on reactor, that are formed at degradation of PET from PWM. This compound will be analyzed by FTIR. The highest yields of gaseous products correspond to the hydrochloric acid that is removed in thermal and catalytic processes of PVC from PWM. 


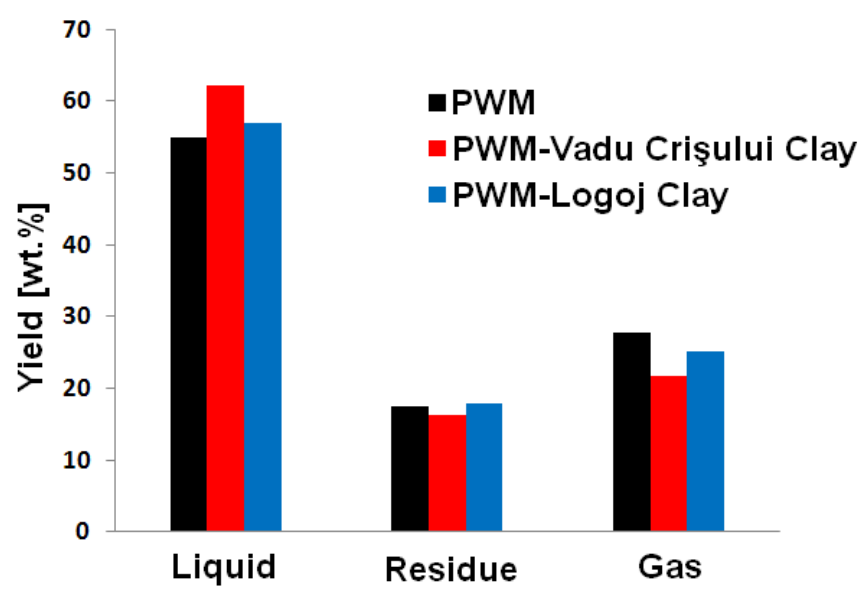

Fig. 6. Yields of products obtained by thermal degradation at $420{ }^{\circ} \mathrm{C}$ of PWM in absence and in presence of the studied catalysts.

\section{Analysis of products}

\section{Liquid products analysis}

The composition of liquid products was determined by GC-MS in order to identification and quantification of hydrocarbons present. The quantification was made by area percentage of TIC (total ion chromatogram). The compounds were identified by comparison of their mass spectra with those from the DATABASE/wiley6.1 spectra library.

In Fig. 7 are given the GC-MS chromatograms of liquid products obtained by thermal and catalytic degradation of PWM.
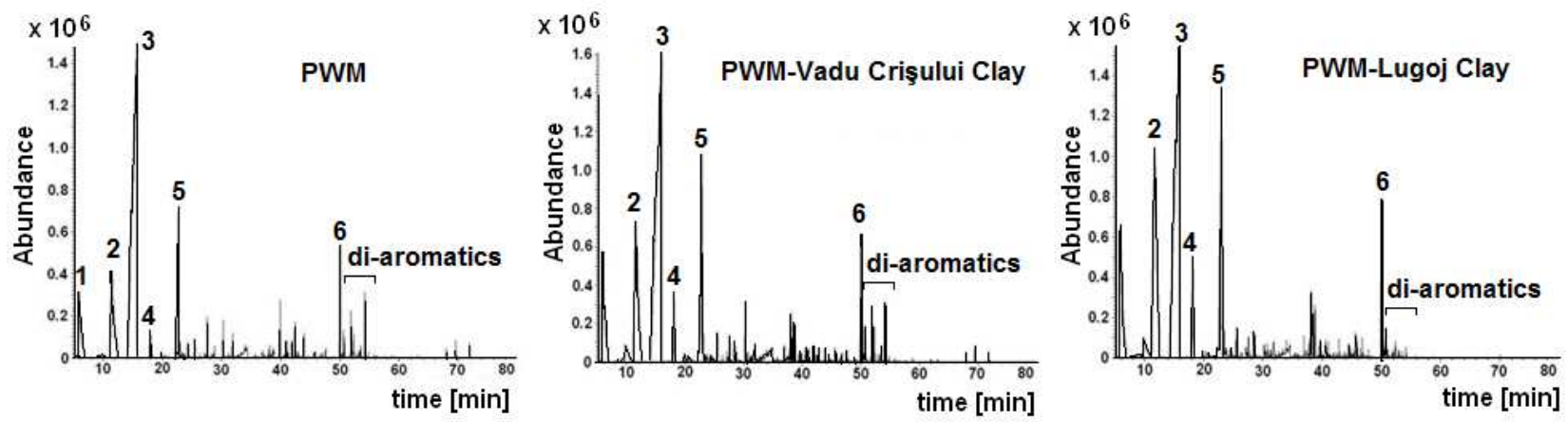

Fig. 7. GC-MS chromatograms of liquid products obtained by thermal degradation at $420^{\circ} \mathrm{C}$ of PWM in absence and in presence of the studied catalyst.

In the chromatograms it can be observed the main compounds: toluene (1, $5.89 \mathrm{~min})$, ethylbenzene (2, $11.72 \mathrm{~min})$, styrene monomer (3, $15.87 \mathrm{~min})$, 1-methylethylbenzene (4, 18.13 $\mathrm{min}), \alpha$-methylstyrene $(\mathbf{5}, 23.00 \mathrm{~min})$ and 1,1'-(1,3-propanediyl)bis benzene $(\mathbf{6}, 50.10 \mathrm{~min})$.

In all cases, the styrene monomer is the major degradation product due to that PWM contains a high amount of polystyrene waste. Also, the small peaks between the compounds 5 and 6 correspond to other compounds found in smaller quantities like: cyclopropyl benzene (25.50 $\mathrm{min}$ ), cloroethyl benzene (27.59 $\mathrm{min})$, octyl cyclopropane $(28.39 \mathrm{~min})$, 2-methyl benzoyl chloride (30.26 $\mathrm{min}$ ) methyl undecene $(38.15 \mathrm{~min})$, 9-octacedene $(45.60 \mathrm{~min})$. The formed chlorinated compounds are obained by PVC degradation. In chromatograms after the $50 \mathrm{~min}$ it can be observed some peaks that are coresponding the some di-aromatics compounds: $4.67 \mathrm{wt} \%$ for PWM, $4.03 \mathrm{wt} . \%$ for PWM-Vadu Crişului Clay and 1.3 wt.\% for PWM-Lugoj Clay.

In Fig. 8 are presented the distribution of compounds from liquids products obtained from thermal degradation of PWM in presence of clay catalysts. 


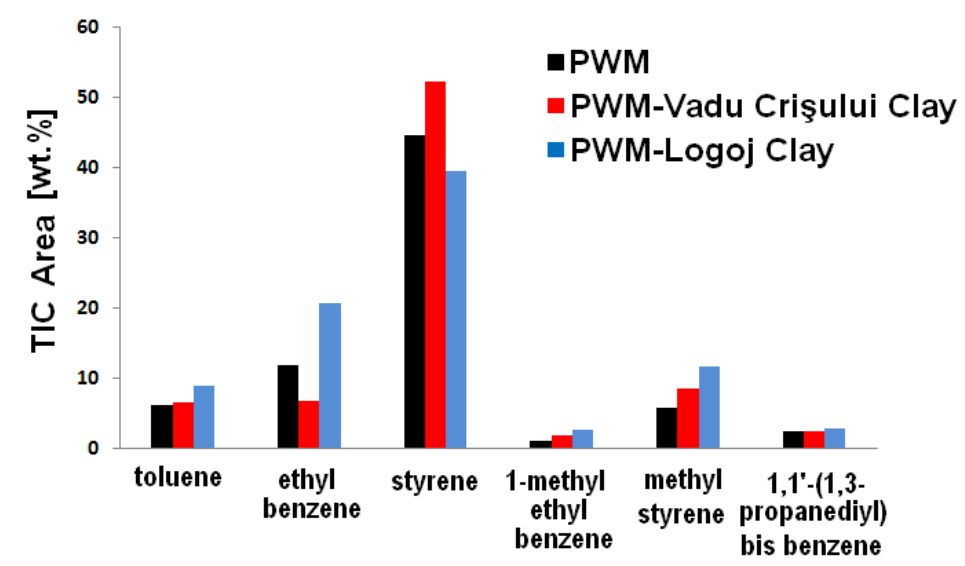

Fig. 8. Distribution of compounds (TIC area, wt.\%) from liquid products obtained by thermal degradation at $420^{\circ} \mathrm{C}$ of PWM in absence and in presence of the studied catalyst.

The GC-MS results shows that the quantities of styrene monomer obtained in all cases. The largest quantity of the styrene monomer of $52.36 \mathrm{wt} . \%$ are obtained from thermal degradation at $420{ }^{\circ} \mathrm{C}$ of PWM in the presence of Vadu Crişului clay catalyst, the most efficient catalyst. These results are due to the structural properties of this catalyst that presents a high BET surface area of $27.80 \mathrm{~m}^{2} \cdot \mathrm{g}^{-1}$ and the value of meso- and macropore volume of $0.108 \mathrm{~cm}^{3} \cdot \mathrm{g}^{-1}$. The important amounts of ethylbenzene and $\alpha$-methylstyrene of $20.84 \mathrm{wt} . \%$ and $11.7 \mathrm{wt} . \%$ respectively, are formed at thermal degradation of PWM in presence of Lugoj clay catalyst. Also, the all liquid products contain the toluen amounts between 6 and 9 wt.\% and the quantities of 1,1'-(1,3propanediyl)bis benzene of $\sim 3 \mathrm{wt} . \%$.

Structural and molecular information about the hydrocarbons from liquid products are given by spectral analysis. Fourier-transform infrared spectrometry (FTIR) and ultraviolet-visible spectroscopy (UV-Vis) are widely used to interpret the molecular characteristics and structure of organic compounds and are able to quickly discern different bond vibration modes of molecules and transitions between electronic energy levels $[28,29]$.

FTIR spectra presented in Fig. 9 for all liquid products show the same absorption bands that are specific to hydrocarbons compounds. The main absorption bands and the type of the characteristic vibrations (stretching, bending, rocking) of the functional groups of the liquid products obtained from thermal and catalytic degradation of PWM are presented in Table 3.

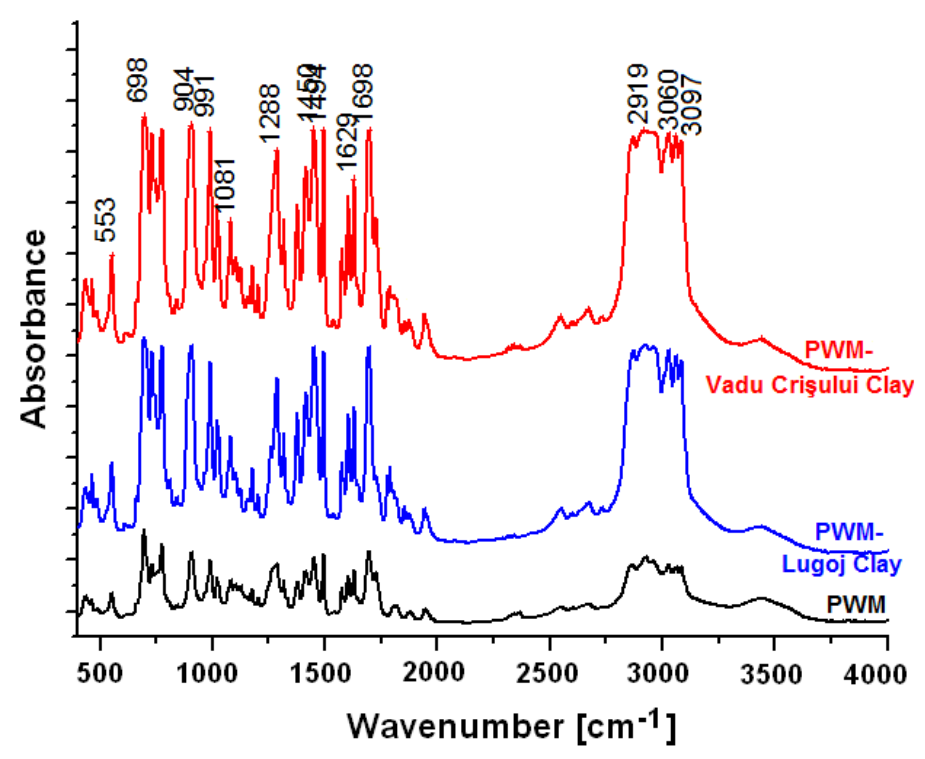

Fig. 9. The FTIR spectra of studied liquid products. 
In FT-IR spectra of liquids products it can be observed two bands at 3097 and $3060 \mathrm{~cm}^{-1}$ that are assigned of the vibration of $\mathrm{C}-\mathrm{H}$ bond in the aromatic ring. In addition, there are strong bands present in the region of $675-900 \mathrm{~cm}^{-1}$ that confirm the presence of aromatic compounds.

Table 3. The assignments of absorption bands of studied liquids [28]

\begin{tabular}{|l|l|l|}
\hline $\begin{array}{l}\text { Group frequency } \\
{\left[\mathrm{cm}^{-1}\right]}\end{array}$ & Functional group & Assignment \\
\hline $3097,3060,3027$ & C-H aromatic ring & C-H stretching \\
\hline 2962 & methyl & $v_{\text {asym }}\left(\mathrm{CH}_{3}\right), \mathrm{C}-\mathrm{H}$ asymmetric stretching \\
\hline 2919 & methylene & $v_{\text {asym }}\left(\mathrm{CH}_{2}\right), \mathrm{C}-\mathrm{H}$ asymmetric stretching \\
\hline 1698 & $\mathrm{C}=\mathrm{O}$ & aromatic $\mathrm{C}=\mathrm{O}$ stretch \\
\hline 1629 & vinyl & $v(\mathrm{C}=\mathrm{C})$, stretching (origin $\mathrm{CH}=\mathrm{CH})$ \\
\hline 1609,1494 & aromatic ring & aromatic ring \\
\hline 1450 & C-CH3 & $\delta_{\text {asym } \text { C-CH3 asymmetric bending }}$ \\
\hline 1288 & C-C-O & C-C-O stretch \\
\hline 1081 & vinyl & C-H in plane bending \\
\hline 991,904 & vinyl & C-H out-of-plane bending \\
\hline 775,698 & mono substituted aromatic ring & C-H out-of-plane bending of aromatic ring \\
\hline
\end{tabular}

The presence of methyl group are indicated by the bands from $2962 \mathrm{~cm}^{-1}$ that correspond to the asymmetric stretching vibration of $\mathrm{C}-\mathrm{H}$ bond. The asymmetric stretching vibration of $\mathrm{C}-\mathrm{H}$ bond in methylene group can be observed at $2919 \mathrm{~cm}^{-1}$. The bands from $1698 \mathrm{~cm}^{-1}$ corespond to aromatic $\mathrm{C}=\mathrm{O}$ stretch vibration from aromatic esters. The intense absorption band from $1629 \mathrm{~cm}^{-1}$ may be assigned to the characteristic vibrational mode of $\mathrm{C}=\mathrm{C}$ bond (origin $\mathrm{CH}=\mathrm{CH}$ ), and those of 991 and $904 \mathrm{~cm}^{-1}$ are attributed to the C-H out-of-plane bending vibrations corresponding to the vinyl group. The band from 1609 and $1494 \mathrm{~cm}^{-1}$ can be assigned to aromatic ring vibration. The band at 1450 $\mathrm{cm}^{-1}$ can be assigned to asymmetric bending vibration of $\mathrm{C}-\mathrm{CH}_{3}$ group. The aliphatic functional groups observed in the FTIR spectra indicate that these aliphatic groups are probably present as alkyl groups attached to the aromatic rings.

The UV-Vis spectra of organic compounds are associated with transitions between electronic energy levels. The UV-Vis spectra of all liquid products (Fig. 10) show the same absorption maxima and that are specific to electronic transition of molecular species of hydrocarbons from the liquid products [29].

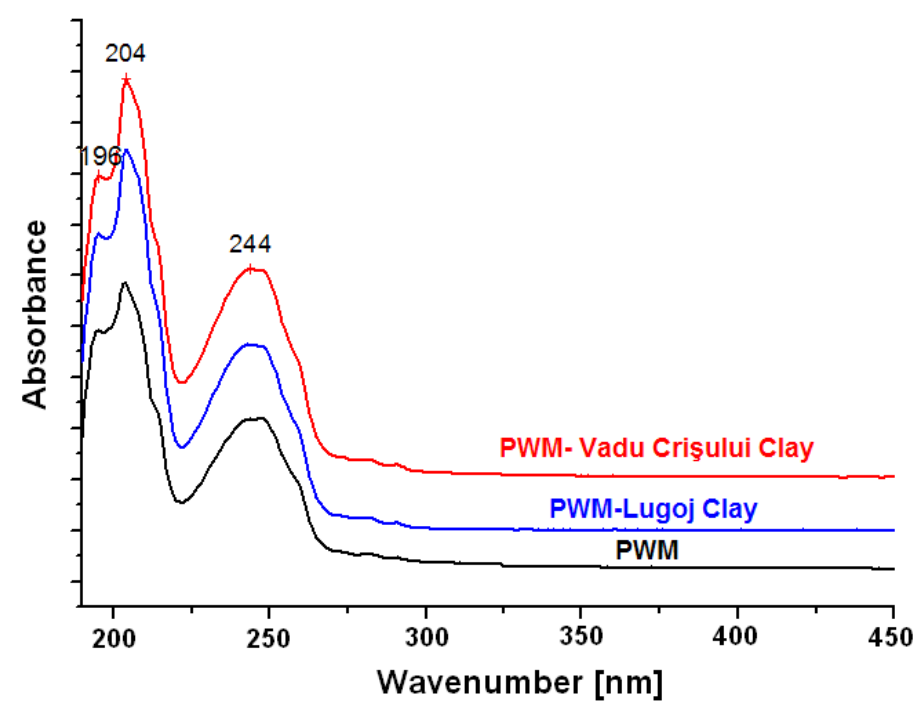

Fig. 10. UV-Vis spectra of studied liquid products 
Thus, it can be observed that the UV-Vis spectra of liquid products studied have two absorption maximum at 196, $204 \mathrm{~nm}$ assigned the presence of unsaturated hydrocarbons with isolated double bonds. The maximum of absorption from $244 \mathrm{~nm}$ of liquid products studied can be correlated with the presence of monoaromatic compounds that may have of condensed alkyl substituents.

The FTIR and UV-Vis results of the liquid product from the thermal and catalytic degradation of PWM are in a good agreement with those obtained by GC-MS analysis of the liquid product.

\section{Solid product analysis}

The solid products that are resulted from thermal and catalytic degradation of PWM contain a solid yellow-brown compound, deposited on wall of the reactor was analyzed by FTIR in order to find structural information about it. In Fig. 11 are presented the FTIR spectrum of this compound that results fron thermal degradation of PET from PWM.

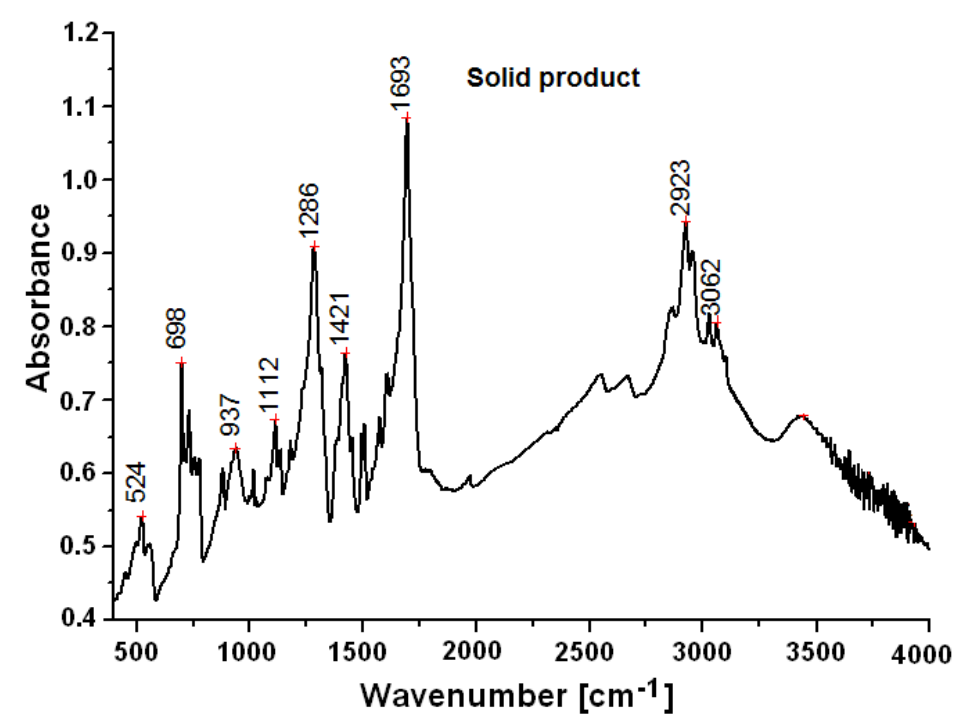

Fig. 11. FTIR spectrum of the solid product obtained from thermal degradation of PWM in presence of Vadu Crişului clay catalyst

In FT-IR spectrum of solid product it can be observed the intense bands at 1693 and $1286 \mathrm{~cm}^{-1}$ that are assigned of the stretching vibrations of aromatic $\mathrm{C}=\mathrm{O}$ and $\mathrm{C}-\mathrm{O}$ bonds respectively, from carboxylic acids groups.

The presence of aromatic ring can be observed by the vibration of $\mathrm{C}-\mathrm{H}$ bond at $3060 \mathrm{~cm}^{-1}$. The asymmetric stretching vibration of C-H bond in methylene group can be observed at $2923 \mathrm{~cm}^{-1}$. In addition, there are strong bands present in the region of $675-900 \mathrm{~cm}^{-1}$ that confirm the presence of aromatic compounds. We can conclude that the solid product can be an aromatic carboxylic acid (e.g. benzoic acid, phthalic acid) that results from thermal decomposition of the poly(ethylene terephthalate).

\section{Conclusions}

The thermal degradation processes at $420{ }^{\circ} \mathrm{C}$ of a plastic waste mixture (PS+PET+PVC) in absence and in presence of two types of natural Romanian clay catalysts were used in this work. The structural parameters of these catalysts influence the yields and the distribution of end-products obtained by thermal and catalytic degradation of the PWM. The yields of liquid products were calculated between 54.98 wt.\% and 62.18 wt.\%. The GC-MS results showed that the liquid fractions contain in principal monoaromatic compounds like styrene (up to $52.36 \mathrm{wt} . \%$ ), toluene, ethylbenzene and $\alpha$-methylstyrene. The highest amounts of styrene come from thermal degradation 
of PS that are the majoritar component in PWM. The Vadu Crişului clay catalyst has been founding the most efficient catalyst in thermal degradation of a PWM. The FTIR and UV-Vis analyses indicated the specific vibration bands or transitions between electronic energy levels of the functional groups from studied products.

The results obtained show that the thermal degradation method of PWM in presence of natural Romanian clay catalysts can be used as recycling method of PWM into liquids oils with potential use in the chemical industry.

\section{Acknowledgements}

This paper was supported by the project "Development and support of multidisciplinary postdoctoral programmes in major technical areas of national strategy of Research - Development Innovation" 4D-POSTDOC, contract no. POSDRU/89/1.5/S/52603, project co-funded by the European Social Fund through Sectoral Operational Programme Human Resources Development 2007-2013.

\section{References}

[1] M. Blazsó, Composition of Liquid Fuels Derived from the Pyrolysis of Plastics, in: J. Scheirs, W. Kamisky (Eds.), Feedstock Recycling and Pyrolysis of Waste Plastics, John Wiley \& Sons Ltd, Chichester, 2006, pp. 315-344.

[2] M. Bajus, E. Hájeková, Thermal cracking of the model seven components mixed plastics into oils/waxes, Petroleum \& Coal 52(3) (2010) 164-172.

[3] Zs. Czégény, E. Jakab, M. Blazsó, T. Bhaskar, Y. Sakata, Thermal decomposition of polymer mixtures of PVC, PET and ABS containing brominated flame retardant: Formation of chlorinated and brominated organic compounds, J. Anal. Appl. Pyrol. 96 (2012) 69-77.

[4] A. López, I. de Marco, B.M. Caballero, M.F. Laresgoiti, A. Adrados, Dechlorination of fuels in pyrolysis of PVC containing plastic wastes, Fuel Process. Technol. 92 (2011) 253-260.

[5] A. López, I. de Marco, B.M. Caballero, M.F. Laresgoiti, A. Adrados, Pyrolysis of municipal plastic wastes: Influence of raw material composition, Waste Management 30 (2010) 620627.

[6] J. Aguado, D. P. Serrano, J. M. Escola, Fuels from Waste Plastics by Thermal and Catalytic Processes: A Review, Ind. Eng. Chem. Res. 47 (2008) 7982-7992.

[7] W. Kaminsky, I.J. Nñnez, Catalytical and thermal pyrolysis of polyolefins, J. Anal. Appl. Pyrol. 79 (2007) 368-374.

[8] I. de Marco, B.M. Caballero, A. López, M.F. Laresgoiti, A. Torres, M.J. Chomon, Pyrolysis of the rejects of a waste packaging separation and classification plant, J. Anal. Appl. Pyrol. 85 (2009) 384-391.

[9] J. Aguado, D.P. Serrano, G. San Miguel, J.M. Escola, J.M. Rodríguez, Catalytic activity of zeolitic and mesostructured catalysts in the cracking of pure and waste polyolefins, J. Anal. Appl. Pyrol. 78 (2007) 153-161.

[10] A. Marcilla, A. Gómez-Siurana, D. Berenguer, Study of the influence of the characteristics of different acid solids in the catalytic pyrolysis of different polymers, App. Catal. A: General 301 (2006) 222-231.

[11] S. Chaianansutcharit, R. Katsutath, A. Chaisuwan, T. Bhaskar, A. Nigo, A. Muto, Y. Sakata, Catalytic degradation of polyolefins over hexagonal mesoporous silica: Effect of aluminum addition, J. Anal. Appl. Pyrol. 80 (2007) 360-368.

[12] M. Olazar, G. López, M. Amutio, G. Elordi, R. Aguado, J. Bilbao, Influence of FCC catalyst steaming on HDPE pyrolysis product distribution, J. Anal. Appl. Pyrol. 85 (2009) 359-365.

[13] J. Aguado, D.P. Serrano, J.M. Escola, A. Peral, Catalytic cracking of polyethylene over zeolite mordenite with enhanced textural properties, J. Anal. Appl. Pyrol. 85 (2009) 352-358. 
[14] A. López, I. de Marco, B.M. Caballero, M.F. Laresgoiti, A. Adrados, A. Torres, Pyrolysis of municipal plastic wastes II: Influence of raw material composition under catalytic conditions, Waste Management 31 (2011) 1973-1983.

[15] A. López, I. de Marco, B.M. Caballero, M.F. Laresgoiti, A. Adrados, A. Aranzabal, Catalytic pyrolysis of plastic wastes with two different types of catalysts: ZSM-5 zeolite and Red Mud, Appl. Catal. B 104 (2011) 211-219.

[16] Q. Zhou, W. Lan, A. Du, Y. Wang, J. Yang, Y. Wu, K. Tang, X. Wang, Lanthania promoted $\mathrm{MgO}$ : Simultaneous highly efficient catalytic degradation and dehydrochlorination of polypropylene/polyvinyl chloride, Appl. Catal. B, 80 (2008) 141-146.

[17] M.N. Siddiqui, H.H. Redhwi, Pyrolysis of mixed plastics for the recovery of useful products, Fuel Process. Technol. 90 (2009) 545-552.

[18] Y. S. González, C. Costa, M.C. Márquez, P. Ramos, Thermal and catalytic degradation of polyethylene wastes in the presence of silica gel, 5A molecular sieve and activated carbon, $\mathrm{J}$. Hazard. Mater. 187 (2011) 101-112.

[19] K.H. Cho, B.S. Jang, K.H. Kim, D.W. Park, Performance of pyrophyllite and halloysite clays in the catalytic degradation of polystyrene, React. Kinet. Catal. Lett. 88(1) (2006) 43-50.

[20] K.H. Cho, D.R Cho, K.H. Kim, D.W. Park, Catalytic degradation of polystyrene using albite and montmorillonite, Korean J. Chem. Eng. 24(2) (2007) 223-225.

[21] S. Jin, K. Cui, H. Guan, M. Yang, L. Liu, C. Lan, Preparation of mesoporous MCM-41 from natural sepiolite and its catalytic activity of cracking waste polystyrene plastics, App. Clay Sci. 56 (2012) 1-6.

[22] G. Manos, Catalytic Degradation of Plastic Waste to Fuel over Microporous Materials, in J. Scheirs, W. Kamisky (Eds.), Feedstock Recycling and Pyrolysis of Waste Plastics, John Wiley \& Sons Ltd, Chichester, 2006, pp. 193-208.

[23] K.S.W. Sing, D.H. Everett, R.A.W. Haul, L. Moscou, R.A. Pierotti, J. Rouquerol, T. Siemieniewska, Pure \& Appl. Chem. 57(4) (1985) 603-619, http://pac.iupac.org/publications/pac/pdf/1985/pdf/5704x0603.pdf

[24] W. Mozgawa, The relation between structure and vibrational spectra of natural zeolites, J. Molec. Struct. 596 (2001)129-137.

[25] Th. Perraki, A. Orfanoudaki, Mineralogical study of zeolites from Pentalofos area, Thrace, Greece, Appl. Clay Sci. 25 (2004) 9-16.

[26] H. Zaitan, D. Bianchi, O. Achak, T. Chafik, A comparative study of the adsorption and desorption of o-xylene onto bentonite clay and alumina, J. Hazard. Mater. 153 (2008) 852859.

[27] O. Korkuna, R. Leboda, J. Skubiszewska-Zięba, T. Vrublevśka, V.M. Guńko, J. Ryczkowski, Structural and physicochemical properties of natural zeolites: clinoptilolite and mordenite Micropor. Mesopor. Mater. 87 (2006) 243-254.

[28] B.C. Smith, Infrared spectral interpretation. A systematic approach, CRC Press, Boca Raton, USA, 1999.

[29] D.H. Williams, I. Fleming, Spectroscopic methods in organic chemistry. Fifth Editions, McGraw-Hill Publishing Company, Berkshire, England, 1995. 